\title{
Eyes open to stem cells: safety trial may pave the way for cell therapy to treat retinal disease in patients
}

\author{
Reinhold J Medina, Desmond B Archer and Alan W Stitt*
}

\begin{abstract}
A clinical trial using human embryonic stem cell (hESC) therapy for an inherited retinal degenerative disease is about to commence. The Advanced Cell Technology (ACT) trial will treat patients with Stargardt's macular dystrophy using transplanted retinal pigment epithelium derived from hESCs. Currently, no effective treatment is available for Stargardt's disease so a stem cell-based therapy that can slow progression of this blinding condition could represent a significant breakthrough. While there are some hurdles to clear, the ACT trial is a fine example of translational research that could eventually pave the way for a range of stem cell therapies for the retina and other tissues.
\end{abstract}

The Medicines and Healthcare Products Regulatory Agency has recently given approval for the first human embryonic stem cell (hESC) clinical trial in the UK. Professor James Bainbridge in partnership with the US company Advanced Cell Technology (ACT) will lead the study at the Moorfields Eye Hospital in London. The trial is the first of its kind in Europe and will investigate the safety and tolerability of using retinal cells derived from hESCs to treat patients with advanced Stargardt's macular dystrophy. This condition is the commonest form of inherited macular degeneration and patients present with central visual loss in their early teens and this is followed by inexorable decline in visual acuity (Figure 1). Currently, no effective treatment is available for Stargardt's disease so a stem cell-based therapy could have a major impact.

Mutations in the gene $A B C A 4$ are responsible for more than $95 \%$ of cases of Stargardt's disease [1]. ABCA4 encodes a photoreceptor-specific transmembrane protein

\footnotetext{
*Correspondence: a.stitt@qub.ac.uk
}

Centre for Vision and Vascular Science, School of Medicine, Dentistry and Biomedical Science, Queen's University Belfast, Royal Victoria Hospital, Belfast BT12 6BA, Northern Ireland, UK that transports retinoids from photoreceptors to the retinal pigmented epithelium (RPE). ABCA4 dysfunction results in the deposition of an ageing pigment called lipofuscin in the RPE, which is normally only associated with much older eyes. Reactive chemical components of lipofuscin can damage RPE function and, subsequently, lead to death of photoreceptors. The rationale for the proposed intervention in Stargardt's disease is that by replacing damaged RPE with healthy cells, the progression of disease might be significantly halted.

The idea of replacing dysfunctional RPE is not novel and different surgical treatments, such as macular translocation or patch graft techniques, have been developed over the past two decades [2-5]. These surgical techniques can have severe complications, including proliferative vitreoretinopathy, submacular haemorrhage and retinal detachment. Therefore, a simple subretinal injection of replacement RPE derived from hESCs was proposed as an alternative. RPE can be generated from either hESCs or human induced pluripotent stem cells (iPSCs) [6], although it has been reported that hESC-derived cells more closely resemble human primary RPE than cells derived from human iPSCs [7]. In addition, it has also been recently demonstrated that iPSCs maintain an epigenetic memory of the tissue of origin, which can influence their directed differentiation and function [8]. While RPE differentiation efficiency may vary between hESC lines, experimental data using animal models with photoreceptor degeneration have shown that transplanted human cells integrate into the host RPE layer with no tumour formation [9]. Importantly, RPE cellular replacement therapy significantly improves vision in treated animals when compared to untreated controls [9]. How this occurs is still not completely certain and there are conflicting data regarding transplanted cell survival and whether they fully integrate into the RPE monolayer or aggregate in clumps [10]. It is also possible that benefits of this cell therapy are actually due to a concomitant nonspecific paracrine effect or immune response rather than the injected cells acquiring a specific RPE phenotype and functioning as such. 

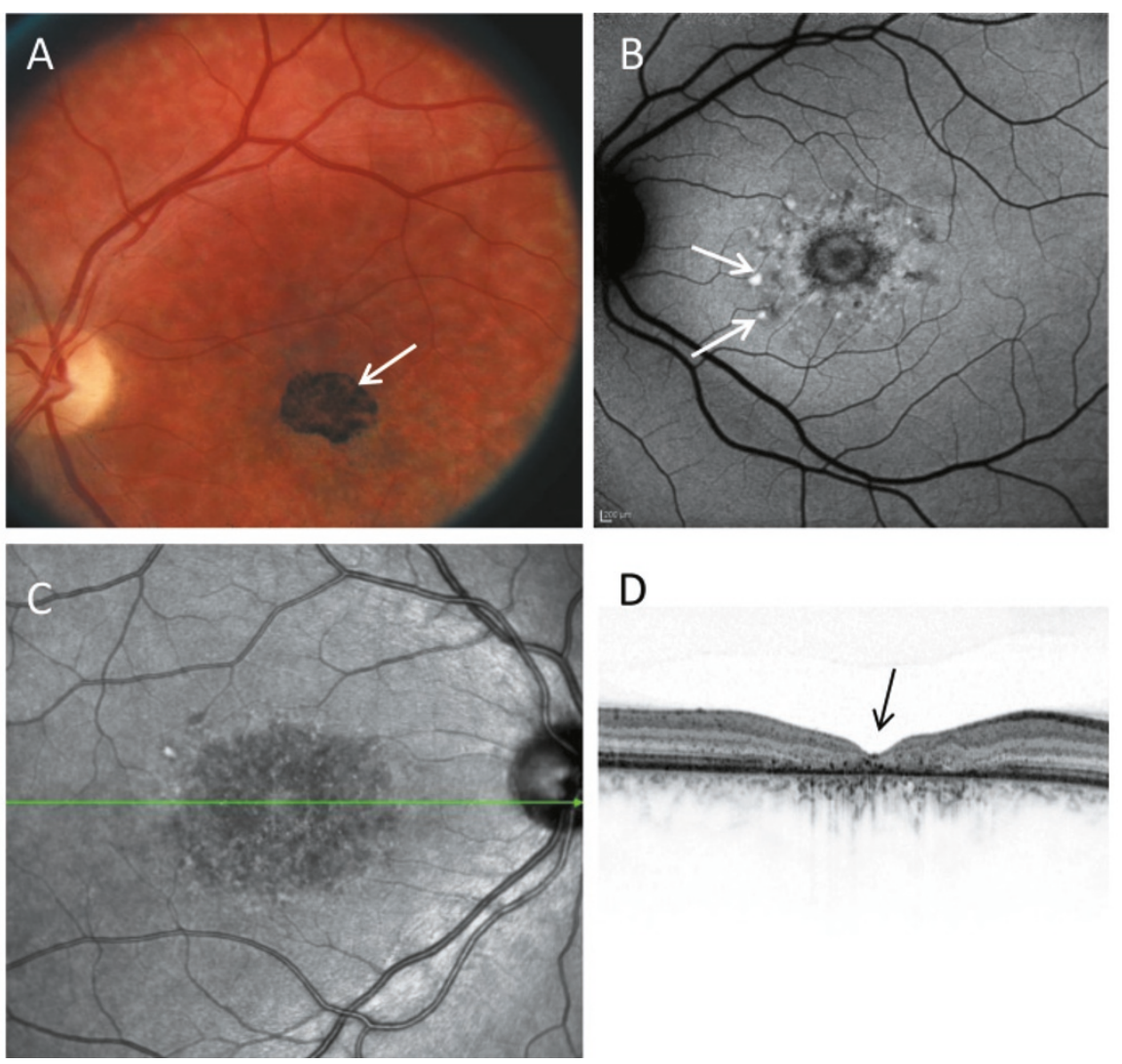

Figure 1. Stargardt's macular dystrophy. (a) Fundus of a patient with advanced Stargardts disease. There are widespread white/yellow deposits at the posterior pole, indicating lipofuscin, RPE deposits and degeneration of the photoreceptors. Of note is the advanced foveal pigmentation at the centre of the macula (arrow). (b) A red free image showing extensive degeneration in the fovea and hyperfluorescent lipofuscin in RPE (arrows). (c,d) Ocular coherence tomography of a 30-year-old Stargardt's patient with vision of 6/36. There is extensive loss of cone photoreceptors evident in the fovea (arrow). Images courtesy of Miss Giuliana Silvestri.

Therefore, the recent announcement of the ACT trial on patients with Stargadt's disease is timely and the balance between risks and benefits will be carefully evaluated. Results from this ACT clinical trial ought to address some critical questions regarding hESC-based therapies in the eye. Will the transplanted hESC-derived RPE carry a risk of tumour formation? Will there be an immunological response by the retina from non HLAmatched foetal RPE? Will immunosuppressants be required?

While stem cell therapy holds promise for regenerating many cells and tissues, the retina can be regarded as an ideal test-bed for cell therapies. It is easily accessible and transplanted cells can be readily visualised during the surgery, visual function can be accurately measured, and complications can often be identified early and addressed with local treatment. This trial will be recruiting only patients with advanced macular degeneration in order to protect against potential adverse events on visual function. This will clearly limit the question of efficacy as there might be a window of opportunity for the cell therapy to be clinically beneficial. For example, if patients' disease is very advanced, then photoreceptor degeneration and RPE dysfunction might not be salvageable. Other similar issues related to advanced disease are changes in RPE substrate (known as Bruch's membrane) and a pro-inflammatory tissue microenvironment could have a negative impact on the efficacy of the cell therapy. Therefore, if this phase I/II ACT trial proves to be safe, further phase III/IV trials to focus on treatment efficacy are warranted. Indeed, since Stargardt's disease shares some important features with age-related macular degeneration, advances made in the ACT study could provide hope for cell therapy in the treatment of this, the most common cause of blindness in the Western world.

Considering all recent advances in cellular and molecular biology, biotechnology, nanotechnology, and immunology, this ACT trial represents the beginning of a new era for stem cell research and translational science. With particular reference to retinal disease, this exciting study could provide meaningful information to guide and encourage the development of other cell therapies that 
can promote blood vessel regeneration in ischaemic retina, neuronal survival or synaptic reconnection of transplanted photoreceptor precursors.

\section{Abbreviations}

ACT, Advanced Cell Technology; hESC, human embryonic stem cell; iPSC, induced pluripotent stem cell; RPE, retinal pigmented epithelium.

\section{Competing interests}

The authors declare that they have no competing interests.

\section{Published: 7 December 2011}

\section{References}

1. Maugeri A, Klevering BJ, Rohrschneider K, Blankenagel A, Brunner HG, Deutman AF, Hoyng CB, Cremers FP: Mutations in the ABCA4 (ABCR) gene are the major cause of autosomal recessive cone-rod dystrophy. Am J Hum Genet 2000, 67:960-966.

2. Machemer R, Steinhorst UH: Retinal separation, retinotomy, and macular relocation: II. A surgical approach for age-related macular degeneration? Graefes Arch Clin Exp Ophthalmol 1993, 231:635-641.

3. Wolf S, Lappas A, Weinberger AW, Kirchhof B: Macular translocation for surgical management of subfoveal choroidal neovascularizations in patients with AMD: first results. Graefes Arch Clin Exp Ophthalmol 1999, 237:51-57.

4. Joussen AM, Heussen FM, Joeres S, Llacer H, Prinz B, Rohrschneider K, Maaijwee KJ, van Meurs J, Kirchhof B: Autologous translocation of the choroid and retinal pigment epithelium in age-related macular degeneration. Am J Ophthalmol 2006, 142:17-30

5. MacLaren RE, Uppal GS, Balaggan KS, Tufail A, Munro PM, Milliken AB, Ali RR,
Rubin GS, Aylward GW, da Cruz L: Autologous transplantation of the retinal pigment epithelium and choroid in the treatment of neovascular agerelated macular degeneration. Ophthalmology 2007, 114:561-570.

6. Bharti K, Miller SS, Arnheiter H: The new paradigm: retinal pigment epithelium cells generated from embryonic or induced pluripotent stem cells. Pigment Cell Melanoma Res 2011, 24:21-34.

7. Liao JL, Yu J, Huang K, Hu J, Diemer T, Ma Z, Dvash T, Yang XJ, Travis GH, Williams DS, Bok D, Fan G: Molecular signature of primary retinal pigment epithelium and stem-cell-derived RPE cells. Hum Mol Genet 2010, 19:4229-4238.

8. Kim K, Doi A, Wen B, Ng K, Zhao R, Cahan P, Kim J, Aryee MJ, Ji H, Ehrlich LI, Yabuuchi A, Takeuchi A, Cunniff KC, Hongguang H, McKinney-Freeman S, Naveiras O, Yoon TJ, Irizarry RA, Jung N, Seita J, Hanna J, Murakami P, Jaenisch R, Weissleder R, Orkin SH, Weissman IL, Feinberg AP, Daley GQ: Epigenetic memory in induced pluripotent stem cells. Nature 2010, 467:285-290.

9. Lu B, Malcuit C, Wang S, Girman S, Francis P, Lemieux L, Lanza R, Lund R: Long-term safety and function of RPE from human embryonic stem cells in preclinical models of macular degeneration. Stem Cells 2009, 27:2126-2135

10. Idelson M, Alper R, Obolensky A, Ben-Shushan E, Hemo I, Yachimovich-Cohen N, Khaner H, Smith Y, Wiser O, Gropp M, Cohen MA, Even-Ram S, BermanZaken Y, Matzrafi L, Rechavi G, Banin E, Reubinoff B: Directed differentiation of human embryonic stem cells into functional retinal pigment epithelium cells. Cell Stem Cell 2009, 5:396-408.

doi:10.1186/scrt88

Cite this article as: Medina RJ, et al:: Eyes open to stem cells: safety trial may pave the way for cell therapy to treat retinal disease in patients. Stem Cell

Research \& Therapy 2011, 2:47. 